\title{
A importância do uso das plantas medicinais, frente ao cenário atual da pandemia causada pelo SARS-CoV-2
}

The importance of the use of medicinal plants, facing the current scenario of the pandemic caused

by SARS-CoV-2

La importancia del uso de plantas medicinales, ante el escenario actual de la pandemia causada por SARS-CoV-2

Esmeraldo Dias da Silva ORCID: https://orcid.org/0000-0001-5036-8346 Universidade do Estado da Bahia, Brasil E-mail: esmeraldoagro@gmail.com Samara Mikaella Santos Matias ORCID: https://orcid.org/0000-0003-0548-975X Universidade do Estado da Bahia, Brasil E-mail: mikaellacat38@gmail.com Bruno Gabriel Amorim Barros ORCID: https://orcid.org/0000-0002-4042-7127 Universidade do Estado da Bahia, Brasil E-mail: brunogabriel123jua@gmail.com

Flávio José Vieira de Oliveira

ORCID: https://orcid.org/0000-0002-4195-4076 Universidade do Estado da Bahia, Brasil E-mail: fvoliveira@uneb.br

\begin{abstract}
Resumo
As plantas medicinais vêm sendo utilizadas desde muito tempo por nossos antepassados, e seus conhecimentos e práticas vêm sendo passados de geração em geração, um hábito que só tende a aumentar dia após dia, principalmente por serem de fácil acesso, podendo ser cultivadas até mesmo no quintal da própria casa. Diante do cenário atual da pandemia, causada pelo SARS-CoV-2, muitas pessoas tem buscado nelas, a prevenção para a doença, alívio dos sintomas ou até mesmo a cura. Tendo em vista os fatos apresentados, objetivou-se com este trabalho, avaliar através de questionário online da Google Forms, compartilhado via mídias sociais, o uso de plantas medicinais contra a Covid-19, prevenção, alívio dos sintomas, se houve um aumento significativo do uso, e apresentar os cuidados que se deve ter com o uso indiscriminado das mesmas. Os dados obtidos foram avaliados de forma quantitativa. Foram realizados revisão de literatura nacional e internacional utilizando artigos publicados, abordando a importância das plantas medicinais, sua eficácia quanto ao uso em doenças causadas por vírus e o uso de produtos fitoterápicos no Brasil. Pode-se concluir que as plantas medicinais são bastante utilizadas pela população, principalmente quando se trata de prevenir alguma doença, como a Covid-19, porém, mesmo as plantas medicinais sendo eficazes e muito utilizadas, deve-se ter cuidado quanto ao uso e não desprezar os conhecimentos científicos.
\end{abstract}

Palavras-chave: Covid-19; Vírus; Alívio de sintomas; Prevenção; Produtos fitoterápicos.

\begin{abstract}
Medicinal plants have been used for a long time by our ancestors, and their knowledge and practices have been passed on from generation to generation, a habit that only tends to increase day by day, mainly because they are easily accessible, and can even be cultivated in the backyard of the house itself. Given the current scenario of the pandemic, caused by SARS-CoV-2, many people have looked to them for disease prevention, symptom relief or even a cure. In view of the facts presented, the objective of this work was to evaluate, through an online questionnaire on Google Forms, shared via social media, the use of medicinal plants against Covid-19, prevention, relief of symptoms, if there was a significant increase of use, and show the precautions that should be taken with their indiscriminate use. The data obtained were quantitatively evaluated. A review of national and international literature was carried out using published articles, addressing the importance of medicinal plants, their effectiveness in terms of their use in diseases caused by viruses and the use of herbal products in Brazil. It can be concluded that medicinal plants are widely used by the population, especially when it comes to preventing some disease, such as Covid-19, however, even though medicinal plants are effective and widely used, care must be taken with their use and do not despise scientific knowledge.
\end{abstract}

Keywords: Covid-19; Virus; Symptom relief; Prevention; Herbal products. 


\begin{abstract}
Resumen
Las plantas medicinales han sido utilizadas durante mucho tiempo por nuestros antepasados, y sus conocimientos y prácticas se han ido transmitiendo de generación en generación, hábito que solo tiende a aumentar día a día, principalmente porque son de fácil acceso, e incluso pueden cultivarse en el patio trasero de la propia casa. Dado el escenario actual de la pandemia, causada por el SARS-CoV-2, muchas personas los han buscado para la prevención de enfermedades, el alivio de los síntomas o incluso una cura. A la vista de los hechos presentados, el objetivo de este trabajo fue evaluar, a través de un cuestionario en línea en Google Forms, compartido a través de las redes sociales, el uso de plantas medicinales contra Covid-19, prevención, alivio de síntomas, si existía una incidencia significativa aumento de uso, y mostrar las precauciones que se deben tomar con su uso indiscriminado. Los datos obtenidos se evaluaron cuantitativamente. Se realizó una revisión de la literatura nacional e internacional utilizando artículos publicados, abordando la importancia de las plantas medicinales, su efectividad en términos de su uso en enfermedades causadas por virus y el uso de productos herbales en Brasil. Se puede concluir que las plantas medicinales son muy utilizadas por la población, sobre todo a la hora de prevenir alguna enfermedad, como Covid-19, sin embargo, aunque las plantas medicinales son efectivas y de amplio uso, se debe tener cuidado con su uso y no desprecie el conocimiento científico.
\end{abstract}

Palabras clave: Covid-19; Vírus; Alivio de sintomas; Prevención; Productos a base de hierbas.

\title{
1. Introdução
}

Atualmente o mundo tem enfrentado uma pandemia causada pelo SARS-CoV-2, conhecido como novo Coronavírus, é o vírus responsável pelo desencadeamento da doença chamada COVID-19 (Cavalcanti et al, 2020). Após 120 dias do primeiro surto, o corona vírus rapidamente se espalhou por cerca de 185 países do mundo, com mais de 2.940 .000 pessoas infectadas e um número superior a 203.822 mortes. Naquele momento, o Estados Unidos da América vinha se apresentando como o epicentro da pandemia com 960.896 casos confirmados e 54.265 mortes confirmadas por COVID-19 (Silva et al, 2020).

Com a rápida disseminação da pandemia no mundo, o sistema de saúde mundial entrou em crise por causa do grande número de contaminados em um pequeno intervalo de tempo. O grande desafio está no tratamento dos pacientes infectados, pois ainda não existe um protocolo de medicamento (Morais et al, 2020). Considerando que as medidas de contenção que estão sendo tomadas ainda não têm se mostrado suficientes, as pessoas começam a buscar alternativas, tanto para prevenção quanto para tratamento, estando, dentre elas, as obtidas de plantas medicinais (Oliveira et al, 2020).

O emprego de plantas medicinais para o tratamento e a cura de doenças é uma prática tão antiga quanto à história do homem. Várias áreas de pesquisa têm buscado avaliar experimentalmente a veracidade das informações sobre as virtudes das plantas medicinais, com base em conhecimentos adquiridos e consolidados durante milhares de anos e repassados através de gerações por aqueles que são os ancestrais da ciência moderna. (Radomsk, 2003).

Foi criado em 2006 pelo Decreto $\mathbf{n}^{\mathbf{0}} 5.813$ A Política Nacional de Plantas Medicinais e Fitoterápicos, tendo o como objetivo geral "garantir à população brasileira o acesso seguro e o uso racional de plantas medicinais e fitoterápicos, promovendo o uso sustentável da biodiversidade, o desenvolvimento da cadeia produtiva e da indústria nacional". (Ministério da Saúde, 2015).

Ainda segundo o (Ministério da Saúde, 2015c), um dos objetivos específicos dessa política, é inserir plantas medicinais, fitoterápicos e serviços relacionados à Fitoterapia no Sistema Único de Saúde (SUS), com segurança, eficácia e qualidade, em consonância com as diretrizes da Política Nacional de Práticas Integrativas e Complementares no SUS. No entanto, mesmo com o incentivo de uma Política Nacional, parece ainda haver carência de informação e de ações no sentido de efetiva implementação dessa prática terapêutica no Sistema de Saúde Brasileiro. Além do mais, faltam estudos para a comprovação científica da eficácia e segurança da utilização dessas plantas como medicamento, sendo que a grande maioria continua a ser utilizada apenas com base no conhecimento do seu uso popular (Gloria, 2012).

Diante do exposto, objetivou-se com este trabalho, avaliar através de pesquisa online por meio de questionário da Google Forms, o uso de plantas medicinais contra a Covid-19, avaliar através da revisão de literatura, o uso das plantas 
medicinais contra doenças causadas por vírus e o uso de produtos fitoterápicos no Brasil. E apresentar os cuidados que se deve ter com o uso indiscriminado das plantas medicinais.

\section{Revisão Bibliográfica}

\subsection{A chegada do vírus SARS-CoV-2 ao Brasil}

O SARS-CoV-2 é o nome designado a um vírus geneticamente relacionado com um grupo SARS-CoV causador da COVID-19. Os primeiros casos humanos da doença causada por ele foram relatados pela primeira vez na cidade de Wuhan na China em dezembro de 2019 (Who, 2020). Em março de 2020, a Organização Mundial da Saúde (OMS) declarou oficialmente que o mundo estava passando por um estágio de pandemia referindo esse termo à distribuição geográfica da doença e não a sua gravidade.

O primeiro caso de COVID-19 no Brasil foi confirmado em 26 de fevereiro de 2020, tratava-se de um homem idoso residente em São Paulo-SP, que havia retornado de uma viagem da Itália (Oliveira et, al. 2020). A partir disso, o Ministério da Saúde, publicou no Diário Oficial da União, a portaria no 356 de 11 de Março de 2020, onde contava com medidas de saúde que poderiam ser adotadas para resposta à emergência de saúde pública. (Ministério da Saúde, 2020). Em junho do mesmo ano o número de infectados se apresentou com um total de 17.122.877 confirmados, 15.596.816 recuperados e uma taxa de 479.515 óbitos confirmados (Corona vírus Brasil, 2021).

Os sintomas da doença podem variar de um resfriado, a uma Síndrome Gripal-SG apresentando uma sensação febril ou febre associada à dor de garganta, dor de cabeça, tosse, coriza, até uma pneumonia severa. Devido ao contágio rápido as principais formas de prevenção são: isolamento social que objetiva a separação de pessoas sintomáticas ou assintomáticas, em investigação clínica e laboratorial e o uso de máscaras e álcool em gel de maneira a evitar a propagação da infecção e transmissão local (Ministério da Saúde, 2020c).

\subsection{O uso de plantas medicinais em doenças causadas por vírus}

O uso das plantas medicinais no tratamento da COVID-19 tem sido prática desde o início da pandemia, ainda que desconhecido medicamentos e vacinas capazes de combater o mesmo, as pessoas vinham buscando em seus conhecimentos medicinais, a prevenção, ou tratamento para os possíveis sintomas causados pela doença. Conhecimentos esses que vem passando de geração em geração, que incluem o uso de plantas medicinais.

Segundo (Henriques et al, 2005) são dois os principais problemas que excluem cerca de $80 \%$ da população mundial dos avanços da medicina: o alto preço com que os medicamentos chegam ao mercado e a ausência de medicamentos para as principais doenças infecto-parasitárias que afligem estes povos. Esses problemas contribuem de forma direta para que as pessoas recorram cada vez mais ao uso das plantas medicinais.

A utilização de plantas no tratamento de doenças no Brasil apresenta influências das culturas indígena, africana e européia (Almeida et al, 2008). Atualmente, pode-se observar um ressurgimento no interesse por produtos naturais como fonte de novas substâncias bioativas. Este renovado interesse, também está associado com avanços nas técnicas de separação, purificação e identificação de misturas complexas de produtos e com a aplicação de vários métodos analíticos. (Barbosa, 2015a).

Segundo (Barbosa, 2015b), a planta medicinal Uncaria tomentosa, membro da família Rutaceae e conhecida como unha-de-gato, é uma grande videira com potencial promissor. Sua atividade antiviral já foi demonstrada em monócitos humanos infectados com vírus da dengue tipo 2 (DENV-2) e tratados com o extrato, in vitro, pela redução de antígenos virais detectados por citometria de fluxo. 
Em trabalho realizado por (Simões, 2010) estudou-se sobre a atividade antiviral da espécie Distictella elongata (Vahl) Urb., pertencente à família Bignoniaceae, frente a dois vírus de DNA: HSV-1 e VACV-WR e um modelo de vírus de RNA: EMC, usando técnicas de microscopia e do MTT. De acordo com os resultados obtidos, apenas o extrato de folhas apresentou atividade antiviral e essa se deu contra o vírus HSV-1.

No estudo de (Silva, 2015), foi avaliada a atividade antiviral do extrato Mikania glomerata Sprengel (guaco), contra os vírus herpes simples tipo I (HSV-1) e tipo II (HSV-2). Como resultados, o extrato de guaco mostrou atividade antiviral contra o HSV-1 e principalmente contra o HSV-2. Mostrou também que a atividade do extrato de guaco foi superior ao padrão primário de cumarina 1,2-benzopirona (presente nas folhas de guaco).

\subsection{Medicamentos fitoterápicos}

Os medicamentos fitoterápicos são aqueles obtidos com emprego exclusivo de matérias-primas ativas vegetais, que possuem seus efeitos comprovados, bem como seus riscos. Não se considera medicamento fitoterápico aquele que inclui na sua composição substâncias ativas isoladas, sintéticas ou naturais, nem as associações dessas com extratos vegetais. (Anvisa, 2020)

Em um estudo feito por (Carvalho et al, 2008a), sobre a situação do registro de medicamentos fitoterápicos no Brasil, pode-se observar que há uma grande concentração de empresas com registro de fitoterápicos na Anvisa, na região Sudeste do país, seguida da região Sul, como também de número de registros concedidos para estas empresas, sendo ainda muito pequena a participação das regiões Norte, Nordeste e Centro-Oeste, observa-se também que a indústria de fitoterápicos segue um padrão de desenvolvimento e distribuição bem próximo da indústria de medicamentos sintéticos, concentrando-se nas regiões Sudeste e Sul do país.

O Brasil precisa avançar no campo da fitoterapia, este avanço depende de uma forte campanha de esclarecimento público, que deve incluir a classe médica, para mostrar a segurança e eficácia das plantas medicinais de uso tradicional, como uma alternativa terapêutica (Ferreira \& Pinto, 2010).

Como estratégia global para a medicina tradicional e a medicina complementar e alternativa para os anos de 2002 a 2005, a Organização Mundial da Saúde, reforçou o compromisso de estimular o desenvolvimento de políticas públicas a fim de inseri-las no sistema oficial de saúde dos seus 191 Estados-membro (Ministério da Saúde, 2006a).

Em maio de 2005, o Ministério da Saúde publicou o documento Política Nacional de Medicina Tradicional e Regulamentação de Medicamentos Fitoterápicos, em que se discute a situação mundial a respeito das políticas de medicina tradicional (MT) e fitoterápico, inclusive o Brasil. (Ministério da Saúde, 2006b).

Em 03 de Maio de 2006, foi aprovada a Política Nacional de Práticas Integrativas e Complementares no SUS (PNPIC), contemplando, entre outras, diretrizes e responsabilidades institucionais para implantação/adequação de ações e serviços de medicina tradicional chinesa/acupuntura, homeopatia, plantas medicinais e fitoterapia, além de instituir observatórios em saúde para o termalismo social/crenoterapia e para a medicina antroposófica no Sistema Único de Saúde (Ministério da Saúde, 2006c).

Foi publicada paralelamente a PNPIC, a Política Nacional de Plantas Medicinais e Fitoterápicos (PNPMF) no dia 26 de Junho de 2006, com o objetivo de garantir o acesso seguro e o uso correto de plantas medicinais e fitoterápicos pela população, promover a utilização sustentável da biodiversidade brasileira e desenvolver a indústria nacional (Ministério da Saúde, 2006d).

Ambas políticas apresentam em suas diretrizes o incentivo à pesquisa e desenvolvimento com relação ao uso de plantas medicinais e fitoterápicos, priorizando a biodiversidade do país. Além disso, estimulam a adoção da Fitoterapia nos programas de saúde pública (Carvalho, et al, 2008b). 
Em um estudo feito por (Damasceno, 2013), em uma Farmácia Magistral no município de João Pessoa-PB, as plantas medicinais mais freqüentes nas preparações fitoterapêuticas, são: Uncaria tomentosa, Camellia sinensis, Valeriana officinalis, Casearia sylvestris, Hamamelis spp., Echinacea spp., Calendula officinalis, Garcinia cambogia, Chamomilla recutita, Ginko biloba, Aesculus hippocastanum, Tribullus terrestres, Passiflora spp., Hypericum perforatum, Maytenus ilicifolia, Erythrina mulungu, Ilex paraguariensis, Arnica spp., Rhamnus purshiana, Gymena sylvestris.

Percebe-se que a adoção dessas políticas, tem sido de grande importância para a sociedade, pois elas oferecem outras formas de tratamentos, faz uso do conhecimento popular, principalmente quanto ao uso das plantas medicinais, que por sua vez, são bastante acessíveis a população (Figueiredo et al, 2014).

\section{Metodologia}

O presente trabalho seguiu a metodologia proposta por (Silva et al, 2021) onde foi aplicado um questionário online na plataforma Google Forms, divulgado no dia 17 de maio de 2021 às 10 h00min e encerrado às 00h00min do dia 20 de maio de 2021. Composto por perguntas relacionadas ao uso das plantas medicinais contra a Covid-19. O mesmo foi divulgado em mídias sociais e compartilhado por terceiros. Os dados obtidos foram avaliados de forma quantitativa.

Foi realizada revisão de literatura nacional e internacional abordando artigos originais, artigos de revisão, editoriais, livros e diretrizes escritas nas línguas portuguesas e inglesas que relatam a importância das plantas medicinais e sua eficácia em doenças causadas por vírus e o uso de produtos fitoterápicos no Brasil. Utilizou artigos publicados nas bases de dados: Scielo, Google acadêmico e PubMed. Os seguintes termos de pesquisa foram utilizados em várias combinações: 1) Plantas medicinais; 2) Viroses; 3) Produtos fitoterápicos. Os dados da revisão foram realizados sem corte de tempo.

\section{Resultados e Discussão}

O presente trabalho desde o início até sua conclusão foi sempre pautado em percepções e teorias unidas em busca de respostas. Os dados descritivos extraídos trouxeram conhecimento sobre a amostra, e representam parcialmente a população. É importante considerar que os questionários on-line são preenchidos sem a oportunidade de o respondente tirar dúvidas, sem o entrevistador observar a dedicação de cada participante na leitura e compreensão da pesquisa, nem sobre o tempo dedicado ou a honestidade durante as respostas, considerando natural que os respondentes possam buscar respostas moralmente e politicamente corretas de acordo como a sua realidade.

A pesquisa contou com um total 105 respondentes, sendo que a maior parte compreende o estado de São Paulo, representando $22,9 \%$ e a menor parte são dos estados do Acre, Tocantins, Rio Grande do Norte, Sergipe, Espírito Santo, Distrito Federal e Mato Grosso, representando 1,0\% cada. (Grafico 1).

Com relação à ocupação dos respondentes do questionário, observa-se no gráfico 2, que 33,3\% corresponde aos trabalhadores, seguidos dos estudantes, que representam $32,4 \%$. 
Gráfico 1- Distribuição percentual por estado.

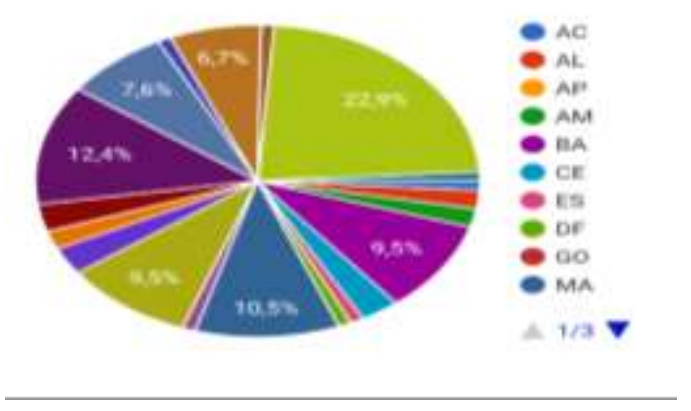

Fonte: Autores, no google forms.

Gráfico 2- Percentual por ocupação.

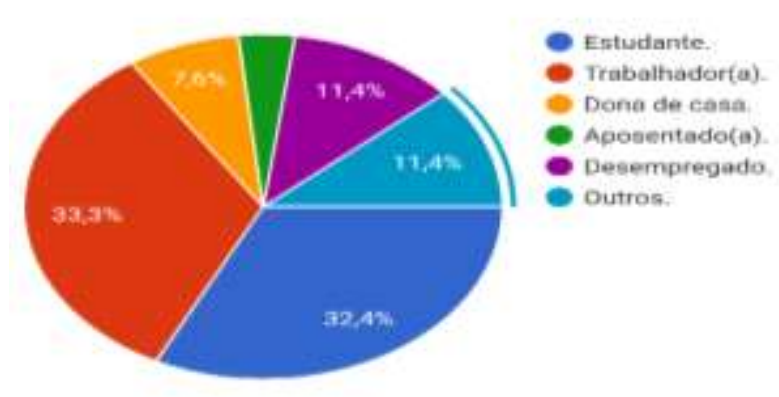

Fonte: Autores, no google forms.

No Gráfico 3, pode-se observar, que das 105 pessoas que responderam o questionário, 105 acreditam no potencial das plantas medicinais, ou seja, um percentual de $100 \%$. Com isso percebe-se, que as plantas medicinais embora possam não trazer resultados significativos na maioria das vezes, e de imediato, são bastante utilizadas. Esse resultado concorda com o que (Veiga Jr. et al, 2005), citaram em seu trabalho, que apesar da medicina alopática estar evoluindo, a fácil obtenção e grande tradição das plantas medicinais, contribuem para a sua utilização.

Gráfico 3- Porcentagem quanto ao potencial das plantas medicinais.

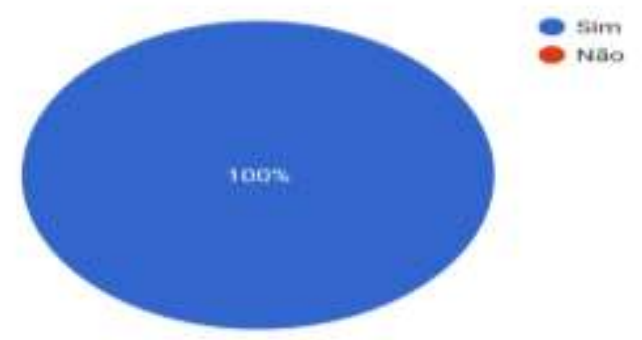

Fonte: Autores, no google forms. 
De acordo com o Gráfico 4, observa-se que houve um aumento de 59\% do consumo de plantas medicinais durante a pandemia. Esse resultado mostra que elas têm sido usadas como forma de prevenção, pois elas têm propriedades que podem aumentar a imunidade. Segundo (Oliveira, 2020), para a manutenção do sistema imunológico, podem ser utilizadas plantas como a cúrcuma, a equinácea, as frutas cítricas, o alecrim e a unha de gato.

Gráfico 4 - Percentual com relação ao aumento do uso de plantas medicinais durante a pandemia.

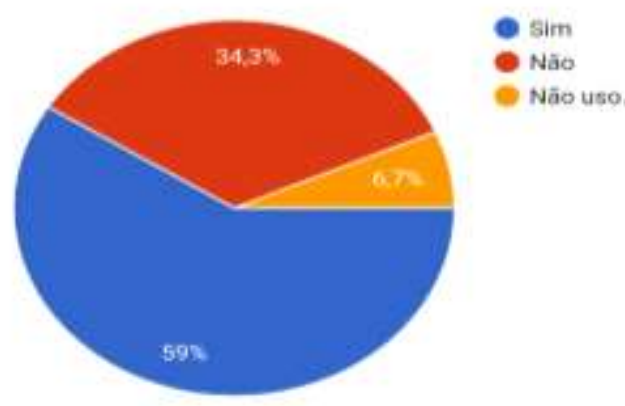

Fonte: Autores, no google forms.

Dentre as formas que as pessoas costumam utilizar as plantas medicinais, destacou-se a forma de chás, compreendendo 92,2\% de 105 pessoas. (Gráfico 5). Esse resultado vai de encontro ao que (McKay \& Blumberg, 2002) citaram em seu trabalho, que depois da água, o chá é a bebida mais consumida popularmente em todo o mundo com um consumo per capita de $120 \mathrm{~mL} /$ dia.

Gráfico 5- Distribuição quanto às formas de uso das plantas medicinais.

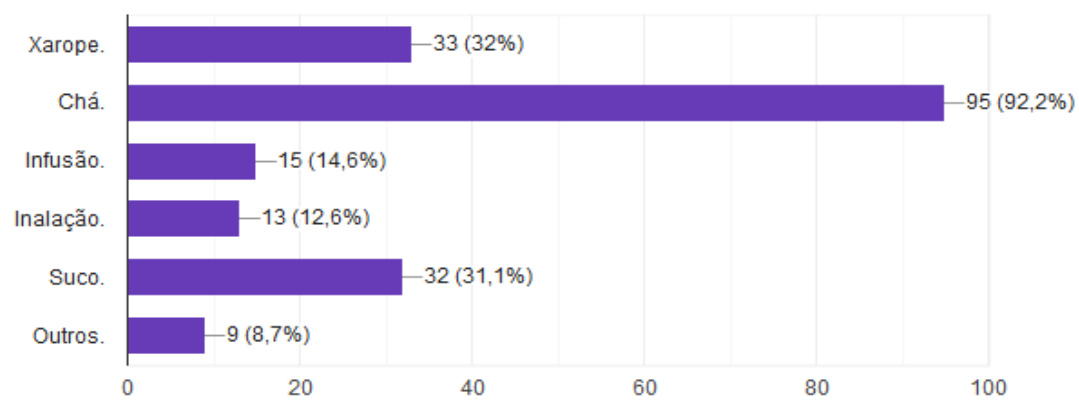

Fonte: Autores, no google forms.

Das 105 pessoas que responderam o questionário, um percentual de 17,1\% confirmou ter sido infectado pelo coronavírus, 13,3\% não tiveram certeza, e 69,5\% não foram infectados, sendo esse último, um resultado satisfatório, pois compreende a maioria, (Gráfico 6). Provavelmente há uma relação desses resultados com os resultados apresentados na figura 4, pois um percentual de 69,5\% não foi infectado pela covid-19, podendo assim indicar mais uma vez, que o aumento do uso das plantas medicinais durante a pandemia, foi como forma de prevenção. 
Gráfico 6. Percentual dos respondentes quanto à infecção pela covid-19.

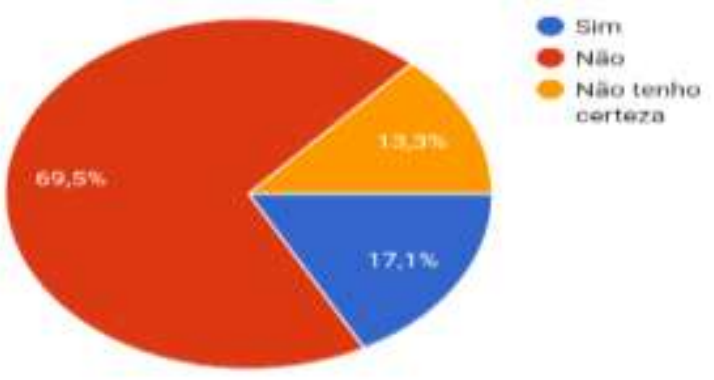

Fonte: Autores, no google forms.

Utilizando os dados do Gráfico 6 e fazendo o somatório das pessoas que foram infectadas pela covid-19, 17,1\%, com as pessoas que não tem certeza se foram infectados 13,3\%, dá um percentual de 30,4\%. Desses, 25,4\% fizeram uso das plantas medicinais para alívio dos sintomas e um percentual de 74,6\% de pessoas não fez uso (Gráfico 7).

De acordo com os dados da Organização Mundial da saúde, cerca de $80 \%$ da população mundial faz uso de algum tipo de erva na busca de alívio de algumas doenças. (Rodrigues, 2004).

Gráfico 7- Percentagem das pessoas infectadas quanto ao uso das plantas medicinais para alívio dos sintomas.

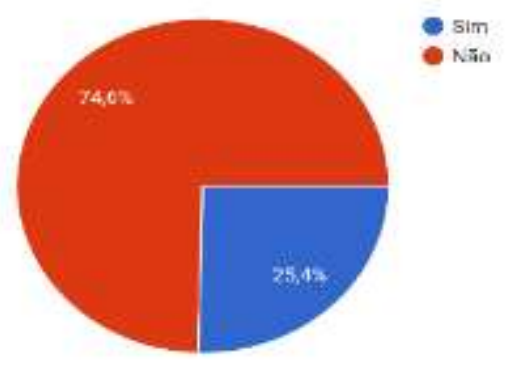

Fonte: Autores, no google forms.

Sobre o uso das plantas medicinais para alívio dos sintomas da covid-19 pelas pessoas que foram infectadas. Um total de 58,7\% respondeu que não obtiveram resultados positivos, $17,5 \%$ responderam talvez, e 23,8\% responderam que obtiveram resultados positivos. (Gráfico 8). Apesar do largo uso que as pessoas fazem das plantas medicinais e da extensão do conhecimento popular, de forma individualizada, o conhecimento das pessoas sobre as plantas medicinais é cheio de imprecisões, principalmente no que diz respeito à forma como são feitas as preparações caseiras, as indicações das plantas e o alcance do uso da Fitoterapia (Figueiredo et al, 2013). O uso das plantas medicinais envolve cuidados essenciais a serem tomados a fim de evitar possíveis intoxicações e insucesso no tratamento de determinada doença. (Vieira et al, 2016).

Para uma utilização adequada das plantas medicinais faz-se necessário o conhecimento sobre a origem, forma de uso, a parte da planta com fins medicinais (folha, flor, sementes e raiz), observando sempre a boa qualidade da matéria-prima vegetal para que realmente cumpra seus propósitos terapêuticos. (Almeida, 2011) 
Gráfico 8- Percentual dos infectados pela covid-19, que utilizaram as plantas medicinais para alívio dos sintomas, se obteve resultados positivos.

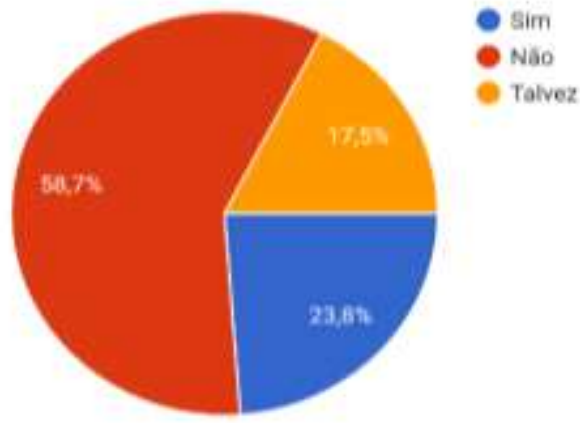

Fonte: Autores, no google forms .

\section{Considerações Finais}

De acordo com os resultados apresentados, pode-se concluir que as plantas medicinais são bastante utilizadas pela população, principalmente quando se trata de prevenir alguma doença, como a covid-19, que a princípio não existia uma vacina ou remédios eficazes para combatê-la. Porém, mesmo as plantas medicinais sendo eficazes e muito utilizadas, deve-se ter cuidado quanto ao uso e não desprezar os conhecimentos científicos.

Diante disso, se faz necessário continuar os estudos sobre o uso de plantas medicinais no tratamento de doenças causadas por vírus, para entender e estabelecer a conservação do conhecimento tradicional e das espécies de plantas, assim como o potencial medicinal, e futuramente promover programas de saúde voltados para a realidade cultural de cada região, valorizando e respeitando os saberes tradicionais locais, que dialoguem com os conhecimentos científicos.

Trabalhos futuros são de extrema importância para que possa surgir dados atualizados e comparados com os já existentes, podendo desta forma detalhar fatores e plantas medicinais que possam trazer benefícios e malefícios ao tratamento contra o Covid-19, assim como sequelas que o vírus possa acarretar em algumas pessoas.

\section{Referências}

Agência Nacional de Vigilância Sanitária - Anvisa. (2021). Ministério da Saúde. https://www.gov.br/anvisa/pt-br

Almeida, A. V., Câmara, C. A. G. \& Marques, E. A. T. (2008). Plantas medicinais brasileiras usadas pelo dr. João Ferreyra da Rosa na "Constituição Pestilencial de Pernambuco" no final do século XVII. Biotemas, Santa Catarina. 21(4), 39-48.

Almeida, M. Z. (2011). Plantas Medicinais [online]. 3rd ed. Salvador: EDUFBA, 2011, 221 p. ISBN 978- 85-232-1216-2. SciELO Books http://books.scielo.org

Barbosa, E.C. (2015). Avaliação da atividade antiviral de extratos vegetais e de fungos contra dengue vírus (Dissertação Mestrado em Ciências da Saúde), Centro de pesquisas René Rachou, Belo Horizonte.

Carvalho, A. C. B., Balbino, E. E., Maciel, A. \& Perfeito, J. P. S. (2008ab). Situação do registro de medicamentos fitoterápicos no Brasil. Revista Brasileira de Farmacognosia, João Pessoa. 18(2), 314-9. DOI: http://dx.doi.org/10.1590/S0102-695X2008000200028

Cavalcanti, I. M. F.; Freitas, G.M; Souza, J.B; Anjos, K.R.B.dos.; Bezerra, M.H. dos. A.; Morais, M.N.de.A.; Sales, S.G.dos.S.; Medeiros, S.M.de.F.R.dos.S.; Silva,T.F.da. \& Silva, T.S.da. (2020). Plantas Medicinais e Seus Possíveis Benefícios no Enfrentamento da Covid-19. Belém-Pa. 6(1), 46 p.

Coronavírus Brasil. Painel coronavírus. (2021). https://covid.saude.gov.br/.

Damasceno, L. M. (2013). Perfil dos Medicamentos Fitoterápicos Mais Comercializados em Farmácia Magistral do Município de João Pessoa-PB. (Trabalho de Conclusão de Curso-Farmácia), Universidade Federal da Paraíba, João Pessoa-PB. 67p.

Ferreira. V.F., \& Pinto. A.C. (2010). A fitoterapia no mundo atual. Química nova, São Paulo. 33(9), p.1829. DOI: https://doi.org/10.1590/S010040422010000900001

Figueiredo, C.A., Gurgel, I.G.D., \& Júnior, G.D.G. (2014). A Política Nacional de Plantas Medicinais e Fitoterápicos: construção, perspectivas e desafios. Physis Revista de Saúde Coletiva, Rio de Janeiro. 24(2), 381-400. DOI: http://dx.doi.org/10.1590/S0103-73312014000200004

Gloria, M. (2012). Plantas Medicinais, Fitoterápicos e Saúde Pública: Um Diagnóstico Situacional Entre Profissionais da Área da Saúde em Anápolis. (2), 76-92, 2012. Goiás. Fronteiras, Anápolis. 
Henriques et al. (2005). Plantas medicinais e Medicamentos Fitoterápicos no Combate a Doenças Negligenciadas: Uma alternativa viável?. 1(1), 30-35. Fitos, Rio de Janeiro.

Mckay, D. L., \& Blumberg, J.B. (2001). The Role of Tea in Human Health: An Update. Journal of the American College of Nutrition, 21, 1-13. DOI: 10.1080 / 07315724.2002.10719187

Ministério da saúde. (2021). Programa de Fitoterápico e Plantas Medicinais. https://www.gov.br/saude/pt-br/acesso-a-informacao/acoes-eprogramas/programa-de-fitoterapico-e-plantas-medicinais.

Ministério da saúde. (2021). Sobre a doença. https://coronavirus.saude.gov.br/sobre-a-doenca\#o-que-e-covid.

Ministério da saúde. (2020) Portaria $n^{\circ}$ 356, de 11 de Março de 2020. https://www.in.gov.br/en/web/dou/-/portaria-n-356-de-11-de-marco-de-2020247538346 .

Ministério da saúde. Política Nacional de Plantas Medicinais e Fitoterápicos. (2006). Brasília-DF., https://bvsms.saude.gov.br/bvs/publicacoes/politica_nacional_fitoterapicos.pdf.

Morais, W. R. S. et al. (2020). Investigação Prospectiva do Novo Coronavírus e de Fármacos Antivirais com Potencial Atividade Terapêutica para o Tratamento de Pacientes Infectados pela COVID-19. Cadernos de Prospecção, Salvador, 13(3), 619-634.

Oliveira, J. R. S. de., (2020). A fitoterapia na pandemia. https://m.uniara.com.br/noticias/47970/a-fitoterapia-na-pandemia/.

Oliveira,W.K.; Duarte, E.; França, G.V.A. \& Garçia, L.P. (2020). Como o Brasil pode deter a covid-19. Epidemiol. Serv. Saúde, 29(3), Brasília.

Organização Mundial da Saúde. (2020). OMS afirma que COVID-19 é agora caracterizada como pandemia. https://www.paho.org/bra/index.php?option=com_content\&view=article\&id=6120:oms-afirma-que-covid-19-e-agora-caracterizada-comopandemia\&Itemid=812.

RadomskI, M.I., (2003). Plantas Medicinais- Tradição e Ciência. Embrapa Floresta.

Rodrigues, V.G.S., Cultivo, (2004). Uso e Manipulação de Plantas Medicinais. Embrapa, Porto Velho-RO.

Silva, E. D. da., Barros, B. G. A., Santos, V. A. dos., \& Oliveira, F. J. V. de. (2021). Agricultura digital em tempos de pandemia. In: Mendonça, M. S.de. (org.). Agronegócio técnicas, inovação e gestão. 1ed.Guarujá-SP: Editora Científica Digital, 2021, v. , p. 14-21.

Silva, F.G.C. (2020) Foods, nutraceuticals and medicinal plants used as complementary practice in facing up the coronavirus (covid-19) symptoms: a review. DOI: https://doi.org/10.1590/SciELOPreprints.317.

Silva, M.E. da. et al. (2015). Avaliação da atividade antiviral do extrato de Mikania glomerata Sprengel (guaco). ( Dissertação de Mestrado em Ciências Farmacêuticas), Universidade Federal de Juíz de Fora, Juíz de Fora.

Simões, R.L. (2010). Fitoquímica, atividade antiviral e antioxidante de Distictella elongata (VAHL) URB. (BIGNONIACEAE). (Dissertação de Mestrado em Ciências Farmacêuticas)- Universidade Federal de Minas Gerais, Belo Horizonte.

Veiga JR., F. V. et al. Plantas Medicinais: Cura Segura? Química Nova, 28(3), 519-528.

Vieira, A.C.M., Andrade, S.R., Seixas, I.M.V., Medeiros, T.K.C. \& Carneiro, L.S.M. (2016). Manual sobre o uso racional de plantas medicinais. 1(1). Rio de Janeiro: Cerceau.

World Health Organization. (2021). Origin of SARS-CoV-2. https://apps.who.int/iris/bitstream/handle/10665/332197/WHO-2019-nCoV-FAQ-Virus_origin2020.1-eng.pdf.. 